\title{
Split-Belt Walking Alters the Relationship between Locomotor Phases and Cycle Duration across Speeds in Intact and Chronic Spinalized Adult Cats
}

\author{
Alain Frigon, ${ }^{1}$ Marie-France Hurteau, ${ }^{1}$ Yann Thibaudier, ${ }^{1}$ Hugues Leblond, ${ }^{2}$ Alessandro Telonio, ${ }^{1}$ \\ and Giuseppe D'Angelo ${ }^{1}$ \\ ${ }^{1}$ Department of Physiology and Biophysics, Faculty of Medicine and Health Sciences, Clinical Research Center of Étienne-Le Bel, Université de Sherbrooke, \\ Sherbrooke, Quebec, Canada, J1H 5N4, and ²Department of Anatomy, Université du Québec à Trois-Rivières, Trois-Rivières, Quebec, Canada, G9A 5H7
}

\begin{abstract}
During overground or treadmill walking, the stance phase and cycle durations are reduced as speed increases, whereas swing phase duration remains relatively invariant. When the speed of the left and right sides is unequal, as is the case during split-belt locomotion or when walking along a circular path, adjustments in stance and swing phases are observed, which could alter the phase/cycle duration relationships. Here, we tested this hypothesis in the left and right hindlimbs of four intact and two chronic spinal-transected adult cats during tied-belt (i.e., equal left and right speeds) and split-belt (i.e., unequal left and right speeds) walking. During split-belt walking, one side (i.e., constant limb) walked at a constant speed while the other side (varying limb) varied its speed from 0.3 to $1.0 \mathrm{~m} / \mathrm{s}$. We show that the phase/cycle duration relationships differed in both hindlimbs concurrently during split-belt walking. Specifically, the slope of the phase/cycle duration relationships for the stance/extension phase increased in the varying limb from tied-belt to split-belt walking, whereas that of the swing/flexion phase decreased. In contrast, in the constant limb, the slope of the phase/cycle duration relationships for the stance/extension phase decreased, whereas that of the swing/flexion phase increased. The results were qualitatively similar in intact and spinal-transected cats, indicating that the modulation was mediated within the spinal cord. In conclusion, we propose that neuronal networks within the spinal cord that control left and right hindlimb locomotion can differentially and simultaneously modulate phase variations when the two sides walk at different speeds.
\end{abstract}

\section{Introduction}

During overground or treadmill walking, cycle duration is reduced as speed increases, which is primarily attributable to a reduction in the duration of the stance phase, whereas the duration of the swing phase is much less affected (for recent reviews, see Gossard et al., 2011; Frigon, 2012). This can be quantified by calculating the slope of the approximately linear relationship between the phases (stance, swing) and the cycle duration (Halbertsma, 1983). The steeper slope of the stance phase/cycle duration relationship is universal in nearly all terrestrial walking species, including insects, birds, rodents, reptiles, dogs, cats, macaques, and humans (Arshavskii et al., 1965; Goslow et al., 1973; Cohen and Gans, 1975; Grillner et al., 1979; Williams, 1981; Jacobson and Hollyday, 1982; Halbertsma, 1983; Vilensky, 1983; Nilsson et al., 1985; Grillner and Dubuc, 1988; Yang et al., 2005;

Received Aug. 17, 2012; revised April 4, 2013; accepted April 8, 2013.

Author contributions: A.F. designed research; A.F., M.-F.H., Y.T., H.L., A.T., and G.D. performed research; A.F., M.-F.H., A.T., and G.D. analyzed data; A.F. wrote the paper.

We thank Danny Gaudreau and Yann Develle for helping with some of the experiments. The present research was funded by grants from the Natural Sciences and Engineering Research Council of Canada to Alain Frigon.

The authors declare no competing financial interests.

Correspondence should be addressed to Dr. Alain Frigon, Université de Sherbrooke, 3001, 12e Avenue Nord, Department of Physiology and Biophysics, Faculty of Medicine and Health Sciences, Sherbrooke, Quebec, J1H 5N4, Canada. E-mail: alain.frigon@usherbrooke.ca.

DOI:10.1523/JNEUROSCI.3931-12.2013

Copyright $\odot 2013$ the authors $\quad 0270-6474 / 13 / 338559-08 \$ 15.00 / 0$
Gabriel and Büschges, 2007; Musselman and Yang, 2007; Gruhn et al., 2009).

However, when the speed of the left and right sides is unequal during walking, adjustments in both the stance and swing phases are observed bilaterally. For example, when walking on a splitbelt treadmill that can independently control the speed of the left and right sides, the stance and swing phases of the "fast" leg are shortened and lengthened, respectively, whereas the stance and swing phases of the "slow" leg are lengthened and shortened, respectively, in cats (Forssberg et al., 1980; Halbertsma, 1983) and humans (Dietz et al., 1994). A similar adjustment in the gait pattern is observed during circular path walking in humans (Courtine and Schieppati, 2003).

Adjusting stance and swing phase durations bilaterally when the two sides walk at different speeds could alter the phase/cycle duration relationships for stance and swing. To test this hypothesis, we evaluated the phase/cycle duration relationships in the left and right hindlimbs of intact and spinal-transected cats that were trained to walk on a split-belt treadmill that could independently control the speed of each side. The phase/cycle duration relationships for stance/extension and swing/flexion were considerably modified during split-belt walking across several speeds. Our results suggest that the neuronal networks, so-called central pattern generators (CPGs), within the spinal cord that control the locomotor pattern of the left and right hindlimbs 
differentially and simultaneously modulate phase variations when the two sides walk at different speeds.

\section{Materials and Methods}

Animals and ethical considerations

All procedures were approved by the Animal Care Committee of the Université de Sherbrooke and were in accordance with policies and directives of the Canadian Council on Animal Care. Before the experiments, animals were housed and fed within designated areas. Six adult cats (one male, five females) weighing between 3.5 and $7.7 \mathrm{~kg}$ were used. Four cats were trained to walk on an animal treadmill with two independently controlled running surfaces $120 \mathrm{~cm}$ long $\times 30 \mathrm{~cm}$ wide (Bertec Corporation). A Plexiglas separator $(120 \mathrm{~cm}$ long $\times 3 \mathrm{~cm}$ high $\times 0.5 \mathrm{~cm}$ wide) was placed between the left and right belts. Two Plexiglas separators $(120 \mathrm{~cm}$ long $\times 50 \mathrm{~cm}$ high) were also placed $30 \mathrm{~cm}$ apart to constrain the animal to walk with the left and right sides separately on the two belts. Cats were given food and affection as reward.

General surgical procedures. Implantation and spinal transection surgeries were performed under aseptic conditions in an operating room with sterilized equipment. Before surgery, the cats were sedated with an intramuscular injection of butorphanol $(0.4 \mathrm{mg} / \mathrm{kg})$, acepromazine $(0.1$ $\mathrm{mg} / \mathrm{kg})$, and glycopyrrolate $(0.01 \mathrm{mg} / \mathrm{kg})$. Induction was done with ketamine/diazepam (0.11 $\mathrm{ml} / \mathrm{kg}$ in a 1:1 ratio, i.m.). Once anesthetized, the cat was quickly intubated with a flexible endotracheal tube, and anesthesia was maintained by adjusting isoflurane concentration as needed (1.5-3\%). The fur overlying the back, stomach, and hindlimbs was shaved with electric clippers, and loose hair was vacuumed. The level of anesthesia was confirmed and adjusted throughout the surgery by monitoring cardiac and respiratory rates, by applying pressure to the paw to detect limb withdrawal, and jaw tone. Body temperature was monitored using a rectal thermometer. During surgery and $\sim 24 \mathrm{~h}$ later, an analgesic $(0.01 \mathrm{mg} / \mathrm{kg}$ buprenorphine) was administered subcutaneously. An antibiotic $(0.1 \mathrm{ml} / \mathrm{kg}$ Convenia) was injected subcutaneously. A transdermal fentanyl patch $(25 \mathrm{mcg} / \mathrm{h})$ was taped to the back of the animal $2-3 \mathrm{~cm}$ from the base of the tail. After surgery, cats were placed in an incubator and closely monitored until they regained consciousness.

Spinal transection and training. In two cats (two females), the spinal cord was completely transected (i.e., spinalized) at low thoracic levels. A small laminectomy was performed between the junction of thoracic vertebrae 12 and 13, the dura was removed, and after local lidocaine application ( $2 \%$ xylocaine), the spinal cord was transected with surgical scissors. Hemostatic material (Surgicel) was inserted within the gap, and muscles and skin were sewn back to close the opening in anatomic layers. The bladder was manually emptied one to two times each day. The cats were monitored daily by experienced personnel. The hindlimbs were frequently cleaned by placing the lower half of the body in a warm soapy bath.

After a few days, cats were trained five times a week to walk on the treadmill. Early after spinal transection, training consisted of two experimenters moving the hindlimbs over the moving treadmill belt to simulate locomotion with similar joint kinematics and paw contacts while the forelimbs were positioned on a fixed platform located $\sim 1 \mathrm{~cm}$ above the belt. After a few days, the skin of the perineal region was stimulated to evoke stepping movements. A Plexiglas separator was placed between the limbs to prevent them from impeding each other because of increased adductor activity. Initially, the experimenter supported the hindquarters by lifting the tail. Recording sessions started once the animals attained a stable locomotor pattern with full weight bearing and consistent plantar foot placement. The experimenter provided equilibrium by holding the tail.

Electromyography. A pair of Teflon insulated multistrain fine wires (AS633; Cooner Wire) were directed subcutaneously from a headmounted 24-pin connector (Hirose Electric) and sewn into the belly of selected hindlimb muscles for bipolar electromyography (EMG) recordings. The EMGs were bandpass filtered $(30-1000 \mathrm{~Hz})$ and amplified (100-5000×) using a 16-channel amplifier (model 3500; AM Systems). EMG data were digitized $(2000 \mathrm{~Hz})$ using custom-made acquisition software. Onsets and offsets of EMG bursts were determined visually using custom-made software. In the spinalized cats, the implantation surgery was performed after the animals had recovered full weight-bearing hindlimb locomotion ( $>1$ month after spinalization).

\section{Experimental protocol}

Each cat performed two sessions of several locomotor episodes of 10-15 cycles of tied-belt and split-belt walking. During tied-belt walking, the left and right forelimbs and hindlimbs of intact cats moved at equal speed, whereas in spinal-transected cats only the hindlimbs moved at equal speed with the forelimbs on a fixed platform. Speeds ranged from 0.3 to $1.0 \mathrm{~m} / \mathrm{s}$. In a given session, the cats performed one block of tied-belt walking and two blocks of split-belt walking with the left and right legs alternating as the varying and constant limbs. The varying limb walked at speeds ranging from 0.3 to $1.0 \mathrm{~m} / \mathrm{s}$, whereas the constant limb maintained the same speed for all episodes. The constant limb speed was set at $0.4 \mathrm{~m} / \mathrm{s}$ in two intact and two spinal-transected cats and at 0.5 and $0.6 \mathrm{~m} / \mathrm{s}$ for the other two intact cats. Speeds of 0.5 and $0.6 \mathrm{~m} / \mathrm{s}$ were used in two intact cats because they had difficulty maintaining consistent locomotion with one side walking at $0.4 \mathrm{~m} / \mathrm{s}$, probably because of their large size $(7.4$ and $7.7 \mathrm{~kg}$ ). The use of different speeds for the constant limb had no visible influence on the results. Episodes of tied-belt or split-belt walking at the different speeds were presented randomly from one session to another, and $\sim 30$ s of rest was given between episodes. 
Data acquisition and analyses

Kinematics. Videos of the hindlimbs were captured with two cameras (Basler) at 60 frames/s. A custom-made Labview program was used to acquire the images and synchronize the cameras. The left- and right-side videos were analyzed offline. Cycle duration was measured from successive foot contacts. Stance duration corresponded to the interval of time from foot contact to the most caudal displacement of the toe relative to the hip (Halbertsma, 1983), whereas swing duration was measured as cycle duration minus stance duration.

EMG. The EMG of several hindlimb muscles was obtained concurrently with video recordings. To determine the duration of the extension phase, the duration of the lateral gastrocnemius (LG), medial gastrocnemius (MG), or vastus lateralis (VL) bursts was measured. LG, MG, and VL burst durations are known to change with stance duration (Halbertsma, 1983). To determine the duration of the flexion phase, the duration of the sartorius (Srt) burst was measured. Srt burst duration is known to change with swing duration (Halbertsma, 1983). Bilateral recordings in extensors and flexors were made concurrently in one intact cat and in the two spinalized cats. In the other three intact cats, unilateral recordings were made from the left or right side. All EMG burst onsets and offsets were tagged manually by the same experimenter (A.F.) using a custom-made software.

The durations for the phases (i.e., stance, swing, extension, and flexion) and the cycle were averaged for each episode. Phase durations were plotted as a function of cycle duration for the left and right hindlimbs during tied-belt and split-belt walking in each session. These are termed phase/cycle duration relationships. We also plotted the duration of the swing phase as a function of the duration of the stance phase of the other hindlimb for the left and right hindlimbs during tied-belt and split-belt walking in each session. These are termed swing/contralateral stance duration relationships. Simple linear regressions were made for phase/ cycle duration and swing/contralateral stance duration relationships. The slopes and coefficients of determination were obtained (SigmaPlot version 11.0; Systat Software).

\section{Results}

Phase/cycle duration relationships during tied-belt and split-belt walking in intact cats

Figure 1 shows episodes of tied-belt (Fig. 1A) and split-belt (Fig. $1 B, C$ ) walking $4 \mathrm{~s}$ after contact of the left hindlimb in an intact cat. The EMGs for a given muscle are at the same vertical scale in all panels. As can be seen, increasing treadmill speed during tiedbelt walking led to a decrease in stance duration bilaterally and in the duration of the left and right LG bursts (Fig. 1A1-A3). Swing phase (i.e., interval between stance) and Srt burst durations bilaterally were less affected by an increase in speed (Fig. 1A1-A3). During split-belt walking with the right hindlimb (constant limb) holding a speed of $0.4 \mathrm{~m} / \mathrm{s}$, a notable change observed was a decrease in the duration of the right swing phase and of the right Srt burst with an increase in speed of the left hindlimb (varying limb) (Fig. 1B1-B3). When the speed ratio was reversed (i.e., left hindlimb constant, right hindlimb varying), the most notable change was a decrease in the duration of the left swing phase and of the left Srt burst with an increase in speed of the right hindlimb (Fig. 1C1-C3). Results from the other session in this cat and from the other three intact cats were qualitatively similar (data not shown).

We performed simple linear regressions to calculate the slope of the relationships between the phases and the cycle, as others have done previously (Grillner et al., 1979; Nilsson et al., 1985; Grillner and Dubuc, 1988; Yakovenko et al., 2005; Musselman and Yang, 2007; Frigon and Gossard, 2009, 2010). Figure 2 shows the phase/cycle duration relationships for the left hindlimb from the session shown in Figure 1. Values for the slope $(b[1])$ and the coefficient of determination $\left(r^{2}\right)$ are indicated on the graphs. During tied-belt locomotion, the slopes of the phase/cycle dura-
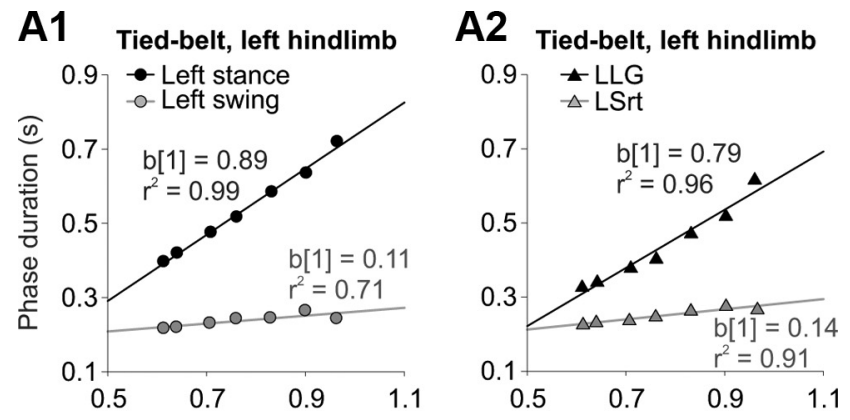

\section{B1 Split-belt (right constant),}

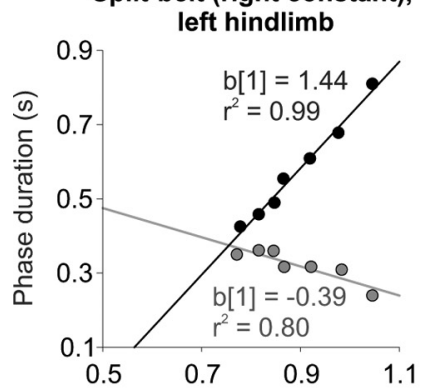

B2 Split-belt (right constant),
left hindlimb

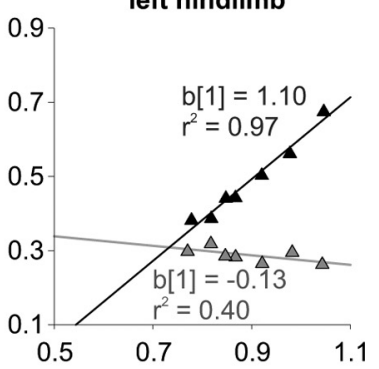

C1 Split-belt (left constant),
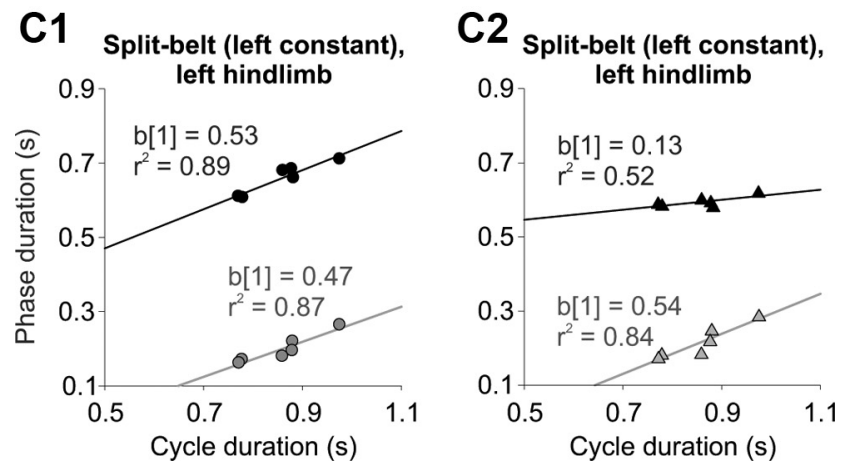

Figure 2. Phase/cycle relationships during tied-belt and split-belt walking in an intact cat. The durations of stance (black circles), swing (gray circles), extension (black triangles), and flexion (gray triangles) phases for the left hindlimb were calculated and plotted as a function of cycle duration. Simple linear regressions are fitted to the phase/cycle relationships during tiedbelt walking $(\boldsymbol{A 1}, \boldsymbol{A} \mathbf{2})$ and during split-belt walking with the right limbs $(\boldsymbol{B} 1, \boldsymbol{B} \mathbf{2})$ and the left limbs (C1, C2) holding a constant speed of $0.4 \mathrm{~m} / \mathrm{s}$. Each data point is the average of $10-15$ cycles. $b[1]$ is the slope of the phase/cycle relationship, and $r^{2}$ is the coefficient of determination. LLG, Left LG; LSrt, Left Srt.

tion relationships for stance (Fig. 2A1) and extension (Fig. 2A2) were positive and much steeper than those of swing (Fig. 2A1) and flexion (Fig. 2A2). During split-belt locomotion with the right hindlimb holding a constant speed of $0.4 \mathrm{~m} / \mathrm{s}$, the slopes of the phase/cycle duration relationships for stance (Fig. 2B1) and extension (Fig. 2B2) were positive and steeper than during tiedbelt walking. In contrast, the slopes of the phase/cycle duration relationships for swing (Fig. 2B1) and flexion (Fig. 2B2) became negative during split-belt walking. During split-belt locomotion with the left hindlimb holding a constant speed of $0.4 \mathrm{~m} / \mathrm{s}$, the slopes of the phase/cycle duration relationships for stance (Fig. 2C1) and extension (Fig. 2C2) were reduced compared with tiedbelt walking. In contrast, the slopes of phase/cycle duration relationships for swing (Fig. 2C1) and flexion (Fig. 2C2) were greater than during tied-belt walking. Thus, the slopes of the stance/cycle and extension/cycle duration increased in the varying limb during split-belt walking, whereas they decreased in the constant limb. Conversely, the slopes of the swing/cycle and flexion/cycle 
duration relationships decreased in the varying limb, whereas they increased in the constant limb.

Phase/cycle duration relationships during tied-belt and split-belt walking in chronic spinalized cats

Forssberg et al. (1980) showed that kittens spinalized soon after birth could adjust to split-belt walking. Here, we show for the first time that cats spinalized as adults can also adjust to split-belt walking. At speeds lower than $0.3 \mathrm{~m} / \mathrm{s}$, the chronic spinalized cats could adopt $2: 1,3: 1$, or $4: 1$ rhythms in the fast and slow hindlimbs (data not shown). The speed difference between the left and right hindlimbs that the two hindlimbs could adopt independent rhythms could be as low as 2:1 (i.e., 0.1:0.2 or $0.2: 0.4 \mathrm{~m} / \mathrm{s}$ ), a much lower ratio than what was reported previously (Forssberg et al., 1980). Because we wanted to evaluate phase/cycle duration relationships when the hindlimbs maintained a 1:1 rhythm, speeds lower than $0.3 \mathrm{~m} / \mathrm{s}$ were not included in the analysis. Figure 3 shows the locomotor pattern of a chronic spinalized adult cat during tied-belt (Fig. 3A) and split-belt (Fig. 3B,C) walking $4 \mathrm{~s}$ after contact of the left hindlimb. The EMGs for a given muscle are at the same vertical scale in all panels. Changes in the locomotor pattern were qualitatively similar to what is shown in Figure 1 in an intact cat. As can be seen, increasing treadmill speed during tied-belt walking led to a decrease in the stance phase bilaterally and in the duration of the left and right VL bursts (Fig. 3A1-A3). The durations of the swing phase (i.e., interval between stance) and of the Srt burst bilaterally were less affected by an increase in speed (Fig. 3A1-A3). During split-belt walking with the right hindlimb (constant limb) holding a speed of $0.4 \mathrm{~m} / \mathrm{s}$, a notable change was a decrease in the duration of the right swing phase and of the right Srt burst with an increase in speed of the left hindlimb (varying limb) (Fig. 3B1-B3). The duration of the left stance phase and of the left VL burst decreased with an increase in speed of the left hindlimb. During splitbelt walking with the left hindlimb (constant limb) holding a constant speed of $0.4 \mathrm{~m} / \mathrm{s}$, the most notable change was a decrease in the duration of the left swing phase and of the left Srt burst with an increase in speed of the right hindlimb (varying limb) (Fig. 3C1-C3). The duration of the right stance phase and of the right VL burst decreased with an increase in speed of the right hindlimb. Results from the other session in this cat and from the other chronic spinalized cat were qualitatively similar (data not shown).

Figure 4 shows the phase/cycle duration relationships for the left hindlimb from the session shown in Figure 3. Changes in the phase/cycle duration relationships in this chronic spinalized cat were qualitatively similar to what is shown in Figure 2 for an intact cat. During tied-belt locomotion, the slopes of the phase/ cycle duration relationships for stance (Fig. 4A1) and extension (Fig. 4A2) were positive and much steeper than those of swing (Fig. 4A1) and flexion (Fig. 4A2). During split-belt locomotion with the right hindlimb (constant limb) holding a speed of 0.4 $\mathrm{m} / \mathrm{s}$, the slopes of the phase/cycle duration relationships for stance (Fig. 4B1) and extension (Fig. 4B2) of the left hindlimb

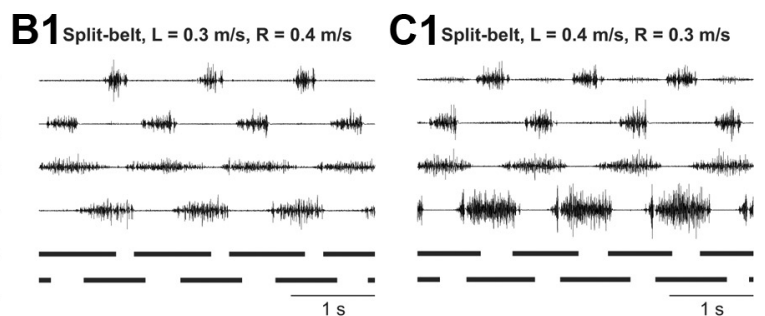

B2

C2
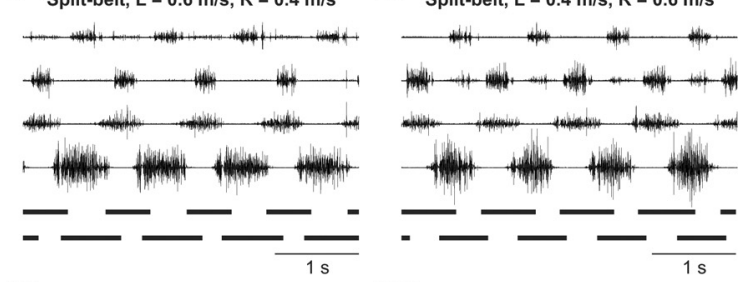

B3

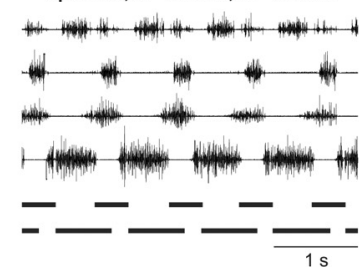

C3

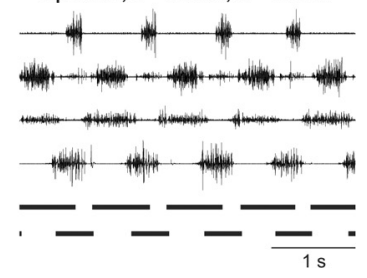

Figure 3. Locomotor pattern during tied-belt and split-belt walking in a chronic spinalized cat. Bilateral recordings from the left episode starting at left hindlimb contact, and the EMG for a given muscle are at the same scale in all panels. The belt speed of the sindicated at the top of each panel.

(varying limb) were steeper than during tied-belt walking. In contrast, the slopes of the phase/cycle duration relationships for swing (Fig. 4B1) and flexion (Fig. 4B2) of the left hindlimb were more negative (i.e., swing) or became negative (i.e., flexion) compared with tied-belt walking. During split-belt locomotion with the left hindlimb (constant limb) holding a speed of $0.4 \mathrm{~m} / \mathrm{s}$, the slopes of the phase/cycle duration relationship for stance (Fig. 4C1) and extension (Fig. 4C2) of the left hindlimb were reduced compared with tied-belt walking. In contrast, the slopes of phase/ cycle duration relationships for swing (Fig. 4C1) and flexion (Fig. $4 C 2$ ) of the left hindlimb were greater than during tied-belt walking. Thus, as in the example shown in Figure 2 for an intact cat, the slopes of the stance/cycle and extension/cycle duration increased in the varying limb during split-belt walking, whereas they decreased in the constant limb. Conversely, the slopes of the swing/cycle and flexion/cycle duration relationships decreased in the varying limb, whereas they increased in the constant limb.

The qualitatively similar results between intact (Figs. 1,2) and chronic spinalized (Figs. 3,4) cats indicate that changes in the phase/cycle duration relationships between tied-belt and splitbelt walking are mediated at the level of the spinal cord.

\section{Phase/cycle duration relationships during tied-belt and split-belt walking across sessions}

Data across sessions were pooled and averaged (intact + spinal). Figure 5 summarizes the data. The left column shows the stance and swing phases, and the right column shows the extension and flexion phases. Figure 5 shows the phase/cycle duration relationships during tied-belt and split-belt walking for the varying and constant limbs across sessions. As shown, the slopes of the stance/ cycle duration and extension/cycle duration relationships were 

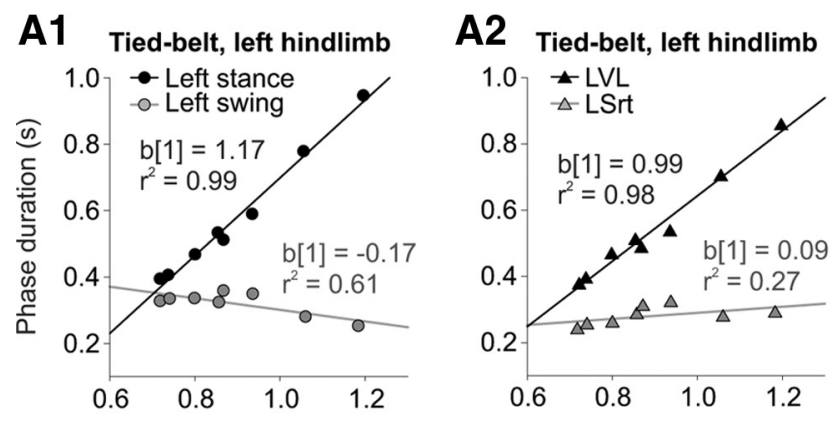

B1 Split-belt (right constant),
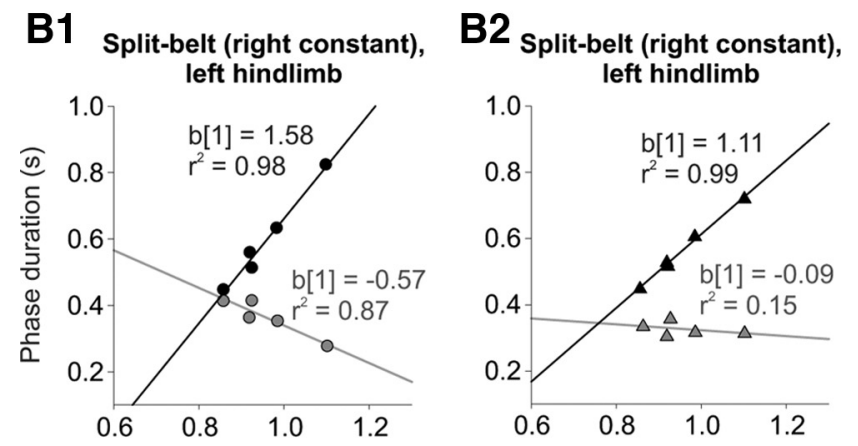

\section{C1 Split-belt (left constant)}

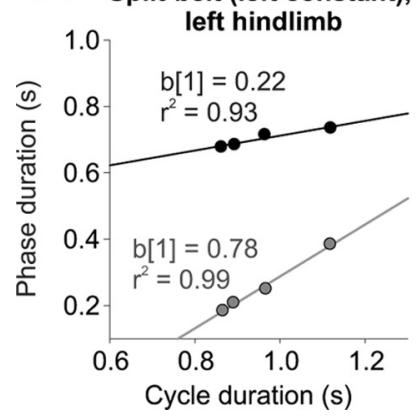

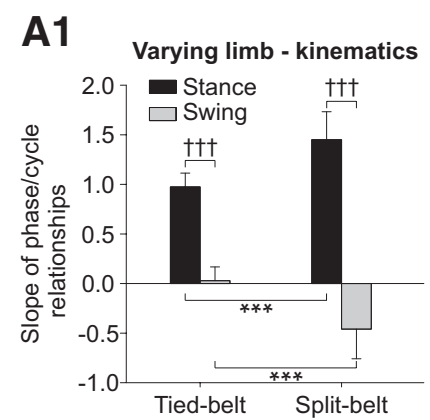
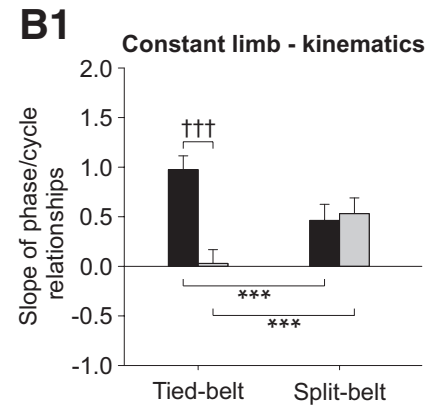

A2

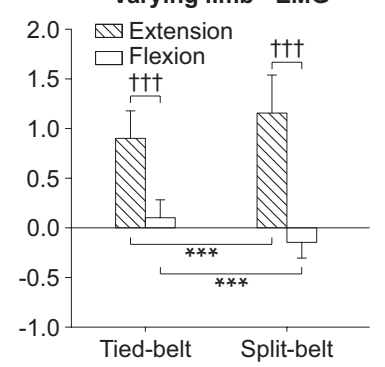

B2

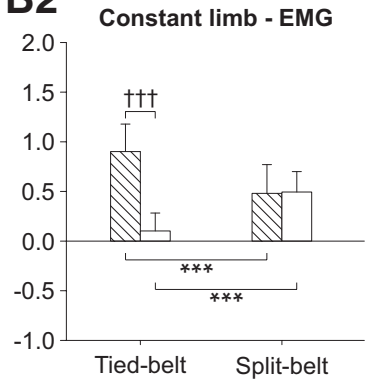

Figure 5. Bar graphs comparing slope values of the phase/cycle relationships across sessions. Each bar is the average of all sessions (intact + spinal, $n=24$ for $(\boldsymbol{A})$ stance and swing phases, $n=17$ for $(\boldsymbol{B})$ extension and flexion phases) for a given condition \pm SD. Asterisks indicate significant differences between tied-belt and split-belt walking for the slope values of the stance/cycle, swing/cycle, extension/cycle, and flexion/cycle relationships, whereas daggers indicate significant differences between stance and swing or extension and flexion during tied-belt and split-belt walking: ${ }^{* *} p \leq 0.01 ;{ }^{* * *, t+t} p \leq 0.001$.

left stance and left swing/right stance relationships were close to zero (Fig. 6A), indicating that a change in stance on one side does not greatly influence the duration of the swing phase on the other side when both hindlimbs walk at the same speed. However, the slope of these relationships changed considerably during splitbelt walking. During split-belt walking with the right hindlimb (constant limb) holding a speed of $0.4 \mathrm{~m} / \mathrm{s}$, the slope of the right swing/left stance relationships increased, whereas that of the left swing/right stance became negative (Fig. 6B). There was a near mirror image with the left hindlimb (constant limb) holding a speed of $0.4 \mathrm{~m} / \mathrm{s}$. The slope of the right swing/left stance relationships became negative, whereas that of the left swing/right stance increased (Fig. 6C). Thus, in the constant limb, an increase in its stance duration is accompanied by a decrease in the swing duration of the varying limb during split-belt walking. In contrast, in the varying limb, an increase in its stance duration is associated with an increase in the swing duration of the constant limb.

Figure 7 shows the slope of the swing/contralateral stance duration relationships in the two hindlimbs during tied-belt and split-belt walking across sessions (intact + spinal). When swing duration of the constant limb was plotted as a function of the stance duration in the varying limb, there was a significant increase in the slope from tied-belt to split-belt walking. When swing duration of the varying limb was plotted as a function of the stance duration in the constant limb, there was a significant decrease in the slope from tied-belt to split-belt walking.

\section{Discussion}

We provide the first detailed account of phase/cycle duration relationships in the left and right hindlimbs of intact and chronic spinalized cats when they walk at several different speeds from each other. Specifically, as speed changed on one side (i.e., varying limb) while the contralateral side maintained a constant

Adjustments in swing and contralateral stance phase durations

Figure 6 shows the relationship between the swing phase and the contralateral stance during tied-belt and split-belt walking in an intact cat. During tied-belt walking, the slopes of the right swing/ 

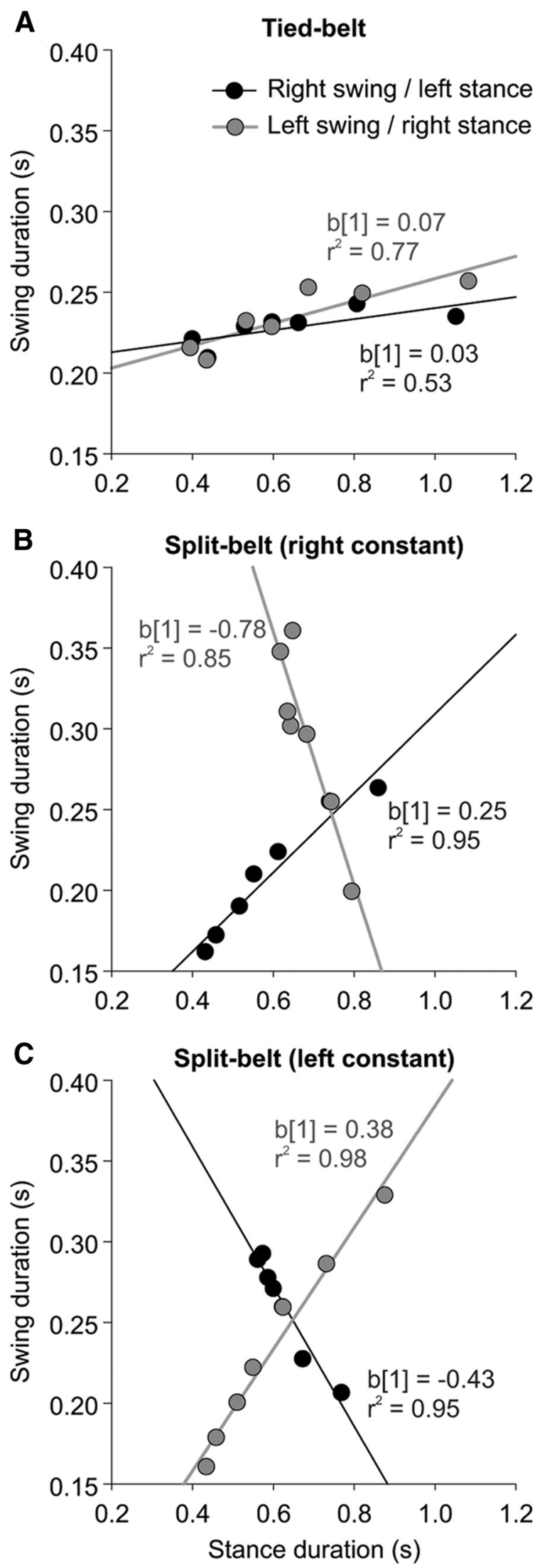

Figure 6. The relationships between swing and the contralateral stance phases during tiedbelt and split-belt walking in an intact cat. Each data point is the average of $10-15$ cycles during tied-belt $(\boldsymbol{A})$ and split-belt $(\boldsymbol{B}, \boldsymbol{C})$ walking. $b[1]$ is the slope of the swing/stance relationship, and $r^{2}$ is the coefficient of determination.

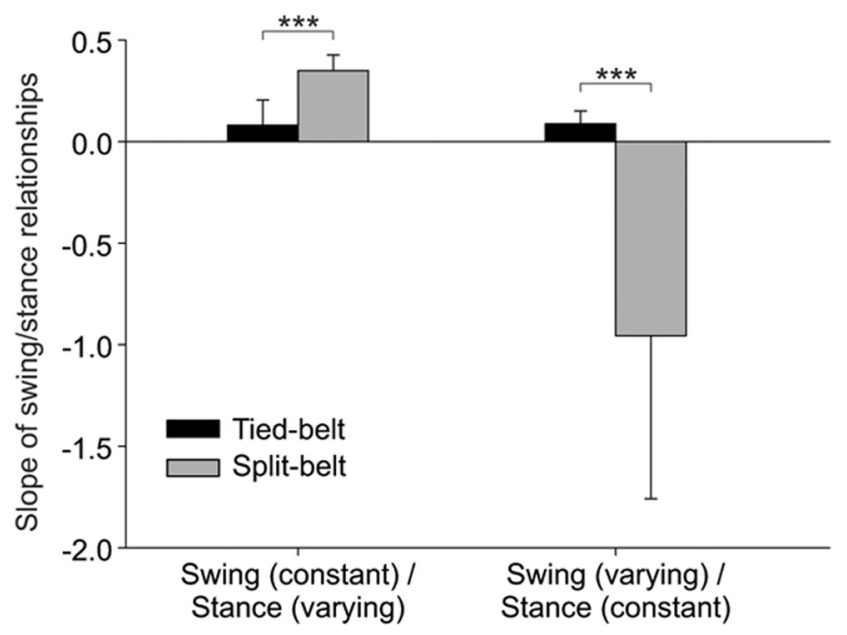

Figure 7. Bar graphs comparing the slopes of the relationships between swing and the contralateral stance phases during tied-belt and split-belt walking in the varying and constant limb across sessions. Each bar is the average of all sessions (intact + spinal, $n=24$ ) \pm SD. ${ }^{* * *} p \leq 0.001$, significant differences between tied-belt and split-belt walking.

speed (i.e., constant limb), both the stance and swing phases varied with cycle duration. However, the phase/cycle duration relationships were different in each leg simultaneously. In the varying limb, the swing/flexion phase decreased linearly with cycle duration, whereas in the constant limb the relationship was positive. Similar changes in the phase/cycle duration relationships were observed in two chronic spinal-transected cats that had recovered hindlimb locomotion through training, indicating that such changes are mediated within the spinal cord.

\section{Task-dependent modulation}

Although previous studies reported that stance and swing phase durations were altered bilaterally during split-belt walking (Forssberg et al., 1980; Halbertsma, 1983; Dietz et al., 1994), they did not evaluate and quantify changes in phase variations as a function of cycle duration across several speeds. Results from the present study clearly show that phase/cycle duration relationships are flexible and can change with task (i.e., from tied-belt to split-belt walking). A recent study also showed that the phase/ cycle duration relationships could be modified after a lateral spinal hemisection and again later after a complete spinalization in adult cats (Martinez et al., 2012). Martinez et al. (2012) proposed that such changes reflected plasticity within spinal locomotor networks. An alternative explanation, based on the results of the present study, is that the asymmetric sensory feedback resulting from the adapted interlimb pattern alters the excitability of neuronal networks controlling phase variations in the hindlimbs, which are themselves essentially intact.

In studies on fictive motor rhythms in decerebrate curarized cats or in isolated spinal cord preparations of neonatal rodents, the slopes of the extension and flexion phase/cycle duration relationships can differ based on the method used to elicit the rhythm and also as a function of the rhythm being studied (for review, see Gossard et al., 2011). For example, during spontaneously occurring fictive locomotion in decerebrate cats, the slope of the extension/cycle duration relationship is much steeper than that of flexion in the majority of episodes (Grillner and Dubuc, 1988; Frigon and Gossard, 2009, 2010; Gossard et al., 2011; Frigon, 2012). This is also the case in spinal-transected decerebrate cats in which the locomotor-like rhythm is induced pharmacologically by L-3,4-dihydroxyphenylalanine or clonidine (Grillner and 
Zangger, 1979; Frigon and Gossard, 2009). In contrast, when the locomotor-like rhythm is evoked by electrical stimulation of the mesencephalic locomotor region (MLR), the slope of the flexion phase/cycle duration relationship is steeper than that of the extension phase in the majority of episodes (Yakovenko et al., 2005). Moreover, during fictive scratch, the slope of the flexion/ cycle duration relationship is much steeper than that of extension (Frigon and Gossard, 2010). These results demonstrate that rhythm-generating networks within the spinal cord can operate by varying either the extension or flexion phases. In the present study, we provide a functional context for the flexible regulation of phase variations.

\section{A sensory-mediated spinal mechanism}

That changes in the phase/cycle duration relationships from tiedbelt to split-belt walking were qualitatively similar in intact and spinal-transected cats indicates that they were mediated at the level of the spinal cord. Such changes are most likely produced by sensory inputs from the periphery that project to spinal locomotor CPGs (Kiehn, 2006; Brownstone and Wilson, 2008; McCrea and Rybak, 2008; Grillner and Jessell, 2009; Guertin, 2009; Kiehn, 2011; Yakovenko, 2011; Frigon, 2012).

Yakovenko et al. (2005) modeled changes in locomotor phases and cycle durations based on data obtained during MLRevoked fictive locomotion in decerebrate cats. Their oscillator model consisted of two mutually inhibitory half-centers: one for flexion and one for extension. In their model, the half-center with the lower background excitation has a higher gain. As such, changes in background excitability produces greater variations in phase duration in this half-center. During walking, the halfcenter with the lower background excitation would be the one controlling flexion, or swing, because the extensor half-center receives disproportionately more sensory inputs attributable to mechanoreceptors responding to foot contact and weight support. Thus, any perturbation that alters background excitation will produce greater swing/flexion phase variations, according to the model.

Although background excitation can be altered in several ways, it could be that inputs related to the stance phase control the duration of the contralateral swing phase when sensory inputs to the spinal cord are asymmetric (e.g., when the speed of the two hindlimbs is different). Evidence in support of this can be found in Figures 6 and 7. During tied-belt walking, the slope of the swing phase relative to contralateral stance is near zero, indicating that, for a given change in stance duration, there is little change in the swing phase of the contralateral hindlimb. However, during split-belt walking, an increase in the stance duration of the limb holding a constant speed is accompanied by a large decrease in the swing duration of the varying limb. In contrast, in the varying limb, an increase in stance duration is associated with a large increase in the swing duration of the constant limb. Based on the model by Yakovenko et al. (2005), such adjustments would predict that extension phase variations increase in the varying limb because of the shorter flexion phase (i.e., the halfcenter with the higher gain), whereas flexion phase variations increase in the constant limb due to the longer flexion phase. This is exactly what occurred in intact and chronic spinalized cats (Figs. 2, 4, 5). Therefore, as a result of adjusting stance and swing bilaterally, phase variations were differentially regulated in both hindlimbs concomitantly. Several reflex pathways originating from peripheral mechanoreceptors have contralateral excitatory and inhibitory actions within the spinal cord and could play a role in coupling the neuronal networks controlling swing and con- tralateral stance phase durations (Sherrington, 1910; Lundberg, 1979; Duysens and Loeb, 1980; Duysens et al., 1980; Gauthier and Rossignol, 1981; Lundberg et al., 1987; Jankowska, 1992; Frigon and Rossignol, 2008; Frigon et al., 2009; Hayes et al., 2012).

At present, we can only speculate as to the specific sensory signals that trigger changes in phase variations within the spinal locomotor CPGs that control the left and right hindlimbs. What is clear from our results is that the neuronal elements within the spinal locomotor CPG governing phase variations do not require supraspinal signals. Pearson and Rossignol (1991) showed that the relationship between a flexor burst (i.e., semitendinosus) and cycle duration was altered by hindlimb position in spinalized decerebrate cats. Although they did not measure the slope of the relationship, it appears that the slope of the flexion/cycle duration relationship decreased when the hip was flexed (Pearson and Rossignol, 1991, their Fig. 4). Frigon and Gossard (2010) also showed that a small dorsiflexion of the ankle increased the slope of the extension/cycle duration relationship during spontaneous fictive locomotion in decerebrate cats. Inputs related to loading could also be involved. For instance, a study in human infants showed that the slope of the extension/cycle duration was greater during treadmill stepping (i.e., more loading during stance), whereas during air-stepping (i.e., greater loading during swing) the slope of the flexion/cycle duration relationship was greater (Musselman and Yang, 2007).

Thus, asymmetric inputs from peripheral mechanoreceptors located in the left and right hindlimbs that sense loading, pressure, and muscle length could play a major role in modifying phase/cycle duration relationships during split-belt walking. However, the exact nature of these signals, the pathways involved, and their interactions within and between locomotor spinal CPGs remain to be systematically investigated. Sensory manipulations (e.g., nerve stimulations, muscle vibration, denervations) will shed more light on this issue.

\section{Functional considerations and concluding remarks}

In summary, the phase/cycle duration relationships observed during normal or tied-belt treadmill locomotion are altered when the two hindlimbs walk at different speeds. Changes in phase/cycle duration relationships are mediated at the spinal level because they were observed in intact and chronic spinalized adult cats. As stated above, studies of fictive locomotion showed that the slopes of the phase/cycle duration relationships for extension and flexion can be modified by sensory inputs from the periphery (Juvin et al., 2007; Musselman and Yang, 2007; Frigon and Gossard, 2010). Our results suggest that asymmetric sensory signals from peripheral mechanoreceptors induced by split-belt walking alter the excitability of the neuronal elements controlling phase variations within the left and right spinal hindlimb locomotor CPGs. The ability to vary the stance/extension and swing/ flexion phases concomitantly could afford a more precise coordination of the limbs during walking.

\section{References}

Arshavski ı̆ IuI, Kots IaM, Orlovskiı̆ GN, Rodionov IM, Shik ML (1965) Study of biomechanics of running dogs (in Russian). Biofizika 10:665671. Medline

Brownstone RM, Wilson JM (2008) Strategies for delineating spinal locomotor rhythm-generating networks and the possible role of $\mathrm{Hb} 9$ interneurones in rhythmogenesis. Brain Res Rev 57:64-76. CrossRef Medline

Cohen AH, Gans C (1975) Muscle activity in rat locomotion: movement analysis and electromyography of the flexors and extensors of the elbow. J Morphol 146:177-196. CrossRef Medline 
Courtine G, Schieppati M (2003) Human walking along a curved path. II. Gait features and EMG patterns. Eur J Neurosci 18:191-205. CrossRef Medline

Dietz V, Zijlstra W, Duysens J (1994) Human neuronal interlimb coordination during split-belt locomotion. Exp Brain Res 101:513-520. Medline

Duysens J, Loeb GE (1980) Modulation of ipsi- and contralateral reflex responses in unrestrained walking cats. J Neurophysiol 44:1024-1037. Medline

Duysens J, Loeb GE, Weston BJ (1980) Crossed flexor reflex responses and their reversal in freely walking cats. Brain Res 197:538-542. CrossRef Medline

Forssberg H, Grillner S, Halbertsma J, Rossignol S (1980) The locomotion of the low spinal cat. II. Interlimb coordination. Acta Physiol Scand 108: 283-295. CrossRef Medline

Frigon A (2012) Central pattern generators of the mammalian spinal cord. Neuroscientist 18:56-69. CrossRef Medline

Frigon A, Gossard JP (2009) Asymmetric control of cycle period by the spinal locomotor rhythm generator in the adult cat. J Physiol 587:46174628. CrossRef Medline

Frigon A, Gossard JP (2010) Evidence for specialized rhythm-generating mechanisms in the adult mammalian spinal cord. J Neurosci 30:70617071. CrossRef Medline

Frigon A, Rossignol S (2008) Short-latency crossed inhibitory responses in extensor muscles during locomotion in the cat. J Neurophysiol 99:989-998. CrossRef Medline

Frigon A, Barrière G, Leblond H, Rossignol S (2009) Asymmetric changes in cutaneous reflexes after a partial spinal lesion and retention following spinalization during locomotion in the cat. J Neurophysiol 102:2667-2680. CrossRef Medline

Gabriel JP, Büschges A (2007) Control of stepping velocity in a single insect leg during walking. Philos Transact A Math Phys Eng Sci 365:251-271. CrossRef Medline

Gauthier L, Rossignol S (1981) Contralateral hindlimb responses to cutaneous stimulation during locomotion in high decerebrate cats. Brain Res 207:303-320. CrossRef Medline

Goslow GE Jr, Reinking RM, Stuart DG (1973) The cat step cycle: hind limb joint angles and muscle lengths during unrestrained locomotion. J Morphol 141:1-41. CrossRef Medline

Gossard JP, Sirois J, Noué P, Côté MP, Ménard A, Leblond H, Frigon A (2011) Chapter 2-the spinal generation of phases and cycle duration. Prog Brain Res 188:15-29. CrossRef Medline

Grillner S, Dubuc R (1988) Control of locomotion in vertebrates: spinal and supraspinal mechanisms. Adv Neurol 47:425-453. Medline

Grillner S, Jessell TM (2009) Measured motion: searching for simplicity in spinal locomotor networks. Curr Opin Neurobiol 19:572-586. CrossRef Medline

Grillner S, Zangger P (1979) On the central generation of locomotion in the low spinal cat. Exp Brain Res 34:241-261. Medline

Grillner S, Halbertsma J, Nilsson J, Thorstensson A (1979) The adaptation to speed in human locomotion. Brain Res 165:177-182. CrossRef Medline

Gruhn M, von Uckermann G, Westmark S, Wosnitza A, Büschges A, Borgmann A (2009) Control of stepping velocity in the stick insect Carausius morosus. J Neurophysiol 102:1180-1192. CrossRef Medline

Guertin PA (2009) The mammalian central pattern generator for locomotion. Brain Res Rev 62:45-56. CrossRef Medline
Halbertsma JM (1983) The stride cycle of the cat: the modelling of locomotion by computerized analysis of automatic recordings. Acta Physiol Scand Suppl 521:1-75. Medline

Hayes HB, Chang YH, Hochman S (2012) Stance-phase force on the opposite limb dictates swing-phase afferent presynaptic inhibition during locomotion. J Neurophysiol 107:3168-3180. CrossRef Medline

Jacobson RD, Hollyday M (1982) A behavioral and electromyographic study of walking in the chick. J Neurophysiol 48:238-256. Medline

Jankowska E (1992) Interneuronal relay in spinal pathways from proprioceptors. Prog Neurobiol 38:335-378. CrossRef Medline

Juvin L, Simmers J, Morin D (2007) Locomotor rhythmogenesis in the isolated rat spinal cord: a phase-coupled set of symmetrical flexion extension oscillators. J Physiol 583:115-128. CrossRef Medline

Kiehn O (2006) Locomotor circuits in the mammalian spinal cord. Annu Rev Neurosci 29:279-306. CrossRef Medline

Kiehn O (2011) Development and functional organization of spinal locomotor circuits. Curr Opin Neurobiol 21:100-109. CrossRef Medline

Lundberg A (1979) Multisensory control of spinal reflex pathways. Prog Brain Res 50:11-28. CrossRef Medline

Lundberg A, Malmgren K, Schomburg ED (1987) Reflex pathways from group II muscle afferents. 2. Functional characteristics of reflex pathways to alpha-motoneurones. Exp Brain Res 65:282-293. CrossRef Medline

Martinez M, Delivet-Mongrain H, Leblond H, Rossignol S (2012) Incomplete spinal cord injury promotes durable functional changes within the spinal locomotor circuitry. J Neurophysiol 108:124-134. CrossRef Medline

McCrea DA, Rybak IA (2008) Organization of mammalian locomotor rhythm and pattern generation. Brain Res Rev 57:134-146. CrossRef Medline

Musselman KE, Yang JF (2007) Loading the limb during rhythmic leg movements lengthens the duration of both flexion and extension in human infants. J Neurophysiol 97:1247-1257. Medline

Nilsson J, Thorstensson A, Halbertsma J (1985) Changes in leg movements and muscle activity with speed of locomotion and mode of progression in humans. Acta Physiol Scand 123:457-475. CrossRef Medline

Pearson KG, Rossignol S (1991) Fictive motor patterns in chronic spinal cats. J Neurophysiol 66:1874-1887. Medline

Sherrington CS (1910) Flexion-reflex of the limb, crossed extension-reflex, and reflex stepping and standing. J Physiol 40:28-121. Medline

Vilensky JA (1983) Gait characteristics of two macaques, with emphasis on relationships with speed. Am J Phys Anthropol 61:255-265. CrossRef Medline

Williams TL (1981) Experimental analysis of the gait and frequency of locomotion in the tortoise, with a simple mathematical description. J Physiol 310:307-320. Medline

Yakovenko S (2011) Chapter 10 - a hierarchical perspective on rhythm generation for locomotor control. Prog Brain Res 188:151-166. CrossRef Medline

Yakovenko S, McCrea DA, Stecina K, Prochazka A (2005) Control of locomotor cycle durations. J Neurophysiol 94:1057-1065. CrossRef Medline

Yang JF, Lamont EV, Pang MY (2005) Split-belt treadmill stepping in infants suggests autonomous pattern generators for the left and right leg in humans. J Neurosci 25:6869-6876. CrossRef Medline 